\title{
O lado de lá da Comunicação. \\ Leitura dos livros organizados por José Carlos Abrantes, A Construção do Olhar (Lisboa, Livros Horizonte: 2005) e Ecrãs em mudança - Dos jovens na Internet ao Provedor de Televisão (Lisboa, Livros Horizonte: 2006)
}

Rafael Paes Henriques*

A investigação no campo das Ciências da Comunicação pode se ocupar de muitos aspectos do complexo fenómeno comunicacional: os media, seus códigos e seus públicos. Cada uma dessas instâncias abre uma série de horizontes, permite diversos ângulos de observação, levanta várias questões. Mas historicamente, a recepção - o lado de lá da comunicação - foi uma unidade de análise menos explorada, apesar de sua importância. É nas pessoas que a comunicação acontece; é nelas que o processo comunicacional se realiza, porém as primeiras teorias explicativas do funcionamento dos media e dos seus efeitos apresentavam os públicos como massas uniformes. Assim, não havia motivo para centrar observações na recepção.

Já há algum tempo, as audiências não são mais vistas de maneira tão redutora. Por isso mesmo, muitas investigações - mesmo que ainda em menor frequência - têm como foco de atenção o lado de lá da comunicação. O momento de consumo das mensagens ganha cada vez mais importância. Esses estudos funcionam como uma espécie de olho que observa o próprio observar. Nessa meta-observação, as pesquisas analisam como as pessoas recebem, descodificam e reinterpretam os sentidos produzidos pelos meios; procuram compreender de que forma as audiências se apropriam dos media e de suas mensagens. No processo de comunicação, o papel dos sujeitos que vêem é, dessa forma, o objecto de reflexão. E é justamente nesses pontos que os artigos de A Construção do Olhar e Ecrãs em Mudança concentram a atenção; é para esse lado que os trabalhos voltam seus olhares.

O espectro de análise é amplo. Em primeiro lugar, o olhar dos espectadores não nasce pronto, mas é construído. Dessa maneira, torna-se fundamental investigar como funcionam os mecanismos de composição das novas formas de ver. A principal pergunta que se coloca é: onde é que hoje se decide o olhar? O primeiro capítulo de $A$ Construção do Olhar se ocupa desses problemas. Os provedores de televisão e suas experiências em França e no Canadá; a natureza ambígua do crítico de TV e o debate sobre seu lugar específico são as reflexões do segundo capítulo de A Construção do Olhar e da terceira parte de Ecrãs em Mudança. As crianças e os jovens são públicos particulares que merecem um olhar próprio e específico. Consideradas mais frágeis e mais susceptíveis a influências dos media, esses espectadores, e a sua relação com as mensagens, frequentemente são objecto de preocupação dos adultos. O terceiro capí-

\footnotetext{
${ }^{*}$ Mestrando em Ciências da Comunicação - Informação e Jornalismo, Universidade do Minho. rafaelpaesh@gmail.com
} 
tulo de A Construção do Olhar e o primeiro de Ecrãs em Mudança analisam como os jovens se apropriam das imagens; como os media actuam na sua sociabilidade; de que maneira os jovens se relacionam e se apropriam da Internet; como as crianças se vêem representadas nos media visuais; como recebem e "digerem" imagens violentas; como se exprimem e se constroem pela linguagem. Terão as crianças direito a participação na vida social? O contexto de recepção do cinema, tão esquecido pela maior parte das investigações, é o objecto de avaliação da última parte de A Construção do Olhar. E o capítulo II de Ecrãs em Mudança se ocupa da educação para os media como forma de oferecer, aos mais jovens, ferramentas de auxílio para que eles possam se localizar e se movimentar com mais facilidade nas intricadas redes que são a TV e a Internet.

\section{0 olhar e a contemporaneidade}

A relação que o público estabelece com as mensagens, no momento da recepção, vem sofrendo muitas transformações. Ao mesmo tempo que o mundo que é representado se torna outro, também as formas de ver se alteram a cada dia. Numa existência cada vez mais organizada pela técnica, desconhecer os mecanismos de construção das imagens constitui uma grande desvantagem para a capacidade de compreensão da realidade. "Ou seja, o conhecimento passa hoje pelo olhar mas muitas vezes esse olhar é fabricado pelas imagens construídas, fabricadas por processos numéricos, de cálculo» (2005: 13). As formas de ver são cada vez mais constituídas por dispositivos maquínicos; são eles que determinam, decidem o nosso olhar. Nesse contexto, a televisão ganha destaque e grande influência no ordenamento social. Os repórteres «[...] não nos dizem o que é, mas, pelo contrário, o que é... é o que eles dizem» (2005: 20).

\section{0 provedor de televisão}

Se é dessa maneira, qual seria, então, o papel dos telespectadores? O que é que lhes resta? Provavelmente pouca coisa. Entretanto a experiência dos provedores de televisão são prova de que muitos deles « [...] recusam o estatuto de telespectadores passivos de imagens e reclamam uma democracia de participação ou, pelo menos, a prática da escuta» (2005: 30). Mesmo sendo a única razão para a existência das emissoras, o público ainda não tem acesso directo aos grandes media. Mas o funcionamento de provedores, pelo menos no serviço público, indica que as audiências começam a ser levadas mais em conta. Os telespectadores querem intervir e contribuir para a melhoria, ou ao menos para uma maior sintonia - entre emissores e receptores - , da programação.

Os provedores canalizam essa vontade de interferir e funcionam como uma espécie de media dos media, pois são intermediários entre as audiências e as televisões, sendo que estas últimas, por sua vez, fazem a ponte entre o mundo e os telespectadores. A tarefa da provedoria é dar um estatuto aos públicos, dar forma ao que ele pensa; tentar colocá-lo no centro do dispositivo. Uma vez que ajudam a dar esse "rosto" às audiências, os provedores podem apontar caminhos para a televisão; estão preparados para ajudar na tomada de decisões. "No turbilhão mediático onde se 
escutam, sobretudo, os ruídos do mundo, a mediação do provedor é um acto de reconhecimento» (2006: 117). Mas os provedores enfrentam resistências internas. Se não é fácil admitir erros e abusos, mais complicado ainda é torná-los públicos. Com efeito, é preciso andar na linha. Apesar das dificuldades, no Canadá, o provedor já aponta alguns reflexos do trabalho, no comportamento dos profissionais. "Os jornalistas são mais sensíveis à necessidade de exactidão e equidade. São mais sensíveis às consequências do que dizem» (2005: 50). Um óptimo resultado, mas que traz consigo um bom motivo de preocupação, pois prova que aquilo que deveria ser o óbvio para todos que trabalham nos media - como a precisão, o rigor, o cuidado e a responsabilidade - nem sempre o é.

\section{Os media, os jovens e as crianças}

Os possíveis prejuízos, causados por determinados conteúdos na formação dos mais jovens, são um exemplo de preocupação das audiências muito frequente. Porém, a identificação dos miúdos com as imagens não é uma relação imediata, nem automática. Um estudo britânico que investigou, por meio de inquéritos, como as crianças se vêem representadas nos media audiovisuais apontou que, muitas vezes, elas duvidam da veracidade daqueles personagens que teoricamente são como elas. Em mais de um escalão etário «[...] houve um nítido reconhecimento das personagens da televisão "como elas" - embora não necessariamente identificação com a sua representação, tanto na forma como no conteúdo» (2005: 85). Isso quer dizer que as crianças se vêem, mas, ao mesmo tempo, não se vêem, porque não se identificam. Era para ser elas, mas, de facto, para elas não é. Assim, um personagem inseguro, imaturo e agressivo não transforma a audiência em crianças estúpidas. Apesar do medo de determinados efeitos, os mais jovens quase sempre sabem colocar as imagens que recebem no seu devido lugar: o da representação. Imagens são apenas imagens e os adultos têm um importante papel nesta distinção, para que elas nunca substituam o real na preferência dos pequenos.

Mas: e quanto às imagens violentas? Se determinados filmes, seriados e até mesmo peças de telejornal são capazes de gerar inquietações em adultos, o que se dirá das consequências para as crianças? A reacção imediata é taxativa: há conteúdos impróprios aos quais os miúdos nunca devem ser expostos. Entretanto, ao invés de privar as crianças das imagens angustiantes, talvez seja mais fecundo que elas as enfrentem acompanhadas, com a ajuda dos pais. A estratégia «[...] não é necessária somente para que delas nos libertemos pessoalmente. É também um meio de se tentar manter o diálogo familiar acerca das imagens que cada um achar inquietantes» (2005: 78).

Uma particularidade da TV reforça essa perspectiva. Ao contrário dos meios digitais, o consumo da televisão continua a ser colectivo. Com efeito, o veículo alcança fundamental importância na sociabilidade juvenil, na medida em que cria interacções no seio da família, ou sobretudo, fora dela. "[...] a recepção da televisão não acontece diante de um televisor mas na antecipação e na produção de colectivos. Para se reflectir sobre o público televisivo, a reflexão deve incidir no social» (2006: 40). Caberia, 
então, aos pais saber aproveitar as oportunidades de diálogo e intercâmbio criadas pela TV.

Mudam-se as tecnologias, mas os receios continuam os mesmos. Com a generalização da Internet, a preocupação com os efeitos dos media na vida dos jovens e na formação das crianças resiste, e ainda se encontra em evidência. Só que uma pesquisa internacional realizada em vários países da Europa e também no Canadá buscou conhecer o fenómeno a partir de um outro horizonte. Os investigadores ocuparam-se em determinar três pontos acerca da relação dos jovens com a rede mundial de computadores: qual a imagem que o jovem tem da Internet; em que condições a utiliza; e como é que o uso da tecnologia se integra em seu quotidiano. Os resultados, nos diversos países pesquisados, não variaram muito e podem atenuar algumas inquietações.

$\mathrm{O}$ uso da Internet é cada vez mais corriqueiro e acontece sobretudo em casa. Ela serve principalmente para diversão, mas também pode se tornar séria - uma ferramenta de estudos, por exemplo. Para os jovens pesquisados, a grande vantagem da rede mundial de computadores é que ela abre a possibilidade para que os usuários exerçam o controlo. Os inquiridos reconhecem a importância da ferramenta, e a grande maioria vê a Internet como uma facilidade tecnológica: sem grandes ódios ou paixões; eles conseguem identificar bem os limites do meio. Por fim, com relação a apropriação da Internet, os pesquisadores concluíram que a rede " [...] depressa se converte numa ocupação entre as outras. Integra-se nas actividades habituais sem ocupar o lugar destas» (2006: 19).

$\mathrm{Na}$ mesma investigação, chama a atenção, no contexto português, o descompasso existente entre a presença da Internet no sistema escolar e seu efectivo uso pedagógico. " [...] no momento da investigação, $83 \%$ dos inquiridos já haviam tido algum contacto com a Internet na escola que frequentam» (2006: 29). Por outro lado, «[...] a escola tem, em geral, uma abordagem fraca, sem profundidade, da Internet» (2006: 30).

\section{A educação para os media}

Num cenário mediático considerado muitas vezes como sendo "desolador e muito pouco edificante em termos éticos, morais ou estéticos» (2006: 73), a educação para os media é apontada como uma estratégia eficiente para dotar as pessoas de instrumentos capazes de reduzir - ou até mesmo impedir - as consequências nocivas dos media.

O ponto de partida é, talvez, consensual: afirma-se « [...] que a escola deve reconhecer a emergência dos media na sociedade, que deve posicionar-se designadamente em termos do seu papel fundamental em relação ao saber» (2006: 56). Mas a partir daí os caminhos são diversos e, em muitos casos, divergentes. Para uns, o trabalho consiste em alertar os jovens sobre os perigos escondidos nas mensagens e sentidos produzidos pelos media; já para outros, educação para os media significa estimular à utilização dos meios como forma de integrar os alunos na era da comunicação em que vivemos. As propostas são variadas porque dependem, directamente, da perspectiva acerca do que os media representam para a educação. As concepções vão desde inimiga mortal - os media só atrapalham - a importante aliada. 
É claro que o segundo horizonte de interpretação se revela mais fértil e pertinente, pois pode contribuir, de maneira significativa, para o estímulo à participação na construção de práticas democráticas. A partir dos media, os jovens podem ser convidados a «[...] construir o seu pensamento, o seu imaginário [...]». Desse modo, os alunos passam a se sentir mais «[...] incentivados a apresentar a visão que têm do mundo» (2006: 71). Numa sociedade tão mediatizada como a nossa, comunicar significa compreender melhor o mundo e também se preparar para nele intervir. 